\title{
Potential of biological phosphorus removal
}

\author{
Nina Zaletova ${ }^{1, *}$, Sergey Zaletov ${ }^{2}$ and Ivan Bulychev ${ }^{1}$ \\ ${ }^{1}$ Moscow State University of Civil Engineering, Department of water supply and wastewater \\ treatment, 26, Yaroslavskoye shosse, Moscow, Russia, 129337 \\ ${ }^{2}$ JSC Eurolos, 100, Dmitrovskoye shosse, Moscow, Russia, 127247
}

\begin{abstract}
The purpose of studies was to assess the potential effectiveness of phosphorus compounds removal from waste water by biological method. Phosphorus removal is very important because of strict standards to phosphate concentration in effluent. But removal of phosphorus by chemical method requires a lot of reagents. Moreover objectives of research were to determine actual efficiency of the biological phosphorus removal. The study shows that under certain technological parameters of biological treatment it is possible to meet strict requirement phosphate removal. This technology can be implemented on existing wastewater treatment plants. The technology of biological phosphorus removal can be combined with the technology of nitrification and denitrification.
\end{abstract}

\section{Introduction}

Technology of biological phosphorus removal selected for investigation based on the ability of activated sludge to consume phosphate actively in aerobic conditions after treatment of recirculated activated sludge in anaerobic conditions, where phosphates are releasing from sludge to liquid phase [1-3]. The technology of biological removal of phosphorus is of great interest to the practice, since it does not require additional fixed costs for the purchase and delivery of reagents. Scheme with deep phosphorus removal includes treatment of waste water in installations of traditional biological treatment that is in primary clarifier, aeration tank and secondary clarifier. Phosphorus release from recirculated activated sludge takes place in special additional installation like secondary clarifier. In the scheme internal flow of waste water with rather high phosphate concentration is formed. The most suitable reagent for phosphorus removal from this flow is lime. In this case P-Ca-containing sludge is formed. This sludge includes two main elements of mineral fertiliser, which is suitable for soil fertilisation and raising its alkalinity. That is why biological phosphorus removal means two tasks to be solved such as deep phosphorus removal without using of reagent in the main treatment installations, and producing of additional product - fertiliser [4-6].

\section{Materials and methods}

Investigations were carried out for several years. The implemented scientific work can be divided on the following stages:

*Corresponding author: naz1604@yandex.ru 
1 - laboratory studies in contact conditions as well as studies in semi-periodical conditions. In the last case activated sludge constantly presented in biological system [7]. Waste water was added in installation periodically and passed through all essential stages of treatment; 2 - research on a pilot plant. The capacity of the plant was $24 \mathrm{~m}^{3} /$ day. Arrangement of the installation includes the same principal scheme of the process, but in the flow mode regime/ It was done in sequential structures: primary sedimentation tank, aeration tank, secondary sedimentation tank, anaerobic treating of recycling sludge in a separate tank;

3 - full scale research on industrial size plant in Tichvin town. Experimental plant was reconstructed according to established technology. Necessary volume of aeration tanks was considered. The capacity of the plant was $4500 \mathrm{~m}^{3} /$ day. Experimental plant was running during three years;

4 - agrochemical studies of P-Ca-containing sludge for usage as fertiliser [8,9].

Each stage of experiments was concentrated on study of certain processes of biological phosphorus removal. Dynamic of phosphate release from sludge and some other characteristics were investigated throughout all types of experiments.

\section{Results}

In the contact conditions it was studied the dynamic of phosphate concentration in active sludge in the anaerobic conditions, when aeration tanks were operated in variable technological modes. Five types of activated sludge were tested: 1-with large dose of sludge and small time of aeration for gravitational sludge separation in the secondary sedimentation tank; 2-the same, but with sludge separation by flotation, 3-from the aeration tank with extended aeration; 4-when the biological nitrification-denitrification takes place; 5 -in the case of bio-chemical treatment. Dynamics of phosphates release in anaerobic conditions are represented on Figure 1.

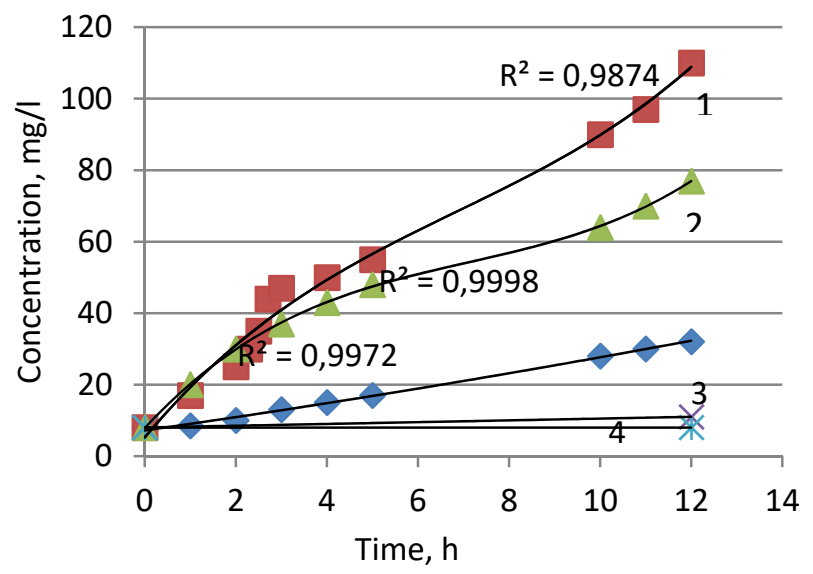

Fig. 1. Phosphates release in anaerobic conditions of activated sludge: 1- gravitational separation; 2flotation; 3- nitrification and denitrification; 4 - bio-chemical treatment.

In all cases (with the exception of bio-chemical process, when phosphates were linked chemically to insoluble compounds (curve 5) and did not stand out in the liquid phase), concentration of phosphates were continuously increased. The the nature of phosphate release was due to the conditions of the preceding aerobic process. Release comes more intensively with high performance biological cleaning process (curve 1), with increasing depth of biological process speed of release decreased (2-3 curves). The lowest rate of 
growth of phosphate content in the anaerobic zone-when nitrification and denitrification (curve 4) took place. It should be noted that the increase of temperature leads to increased release of phosphate. Growth of phosphate concentration in the liquid phase is accompanied by a modification in $\mathrm{Ph}$. Figure 2 reflects changes in $\mathrm{pH}$ in schemas that is of biological treatment with gravitational (curve 1) and flotation (curve 2) separation of sludge.

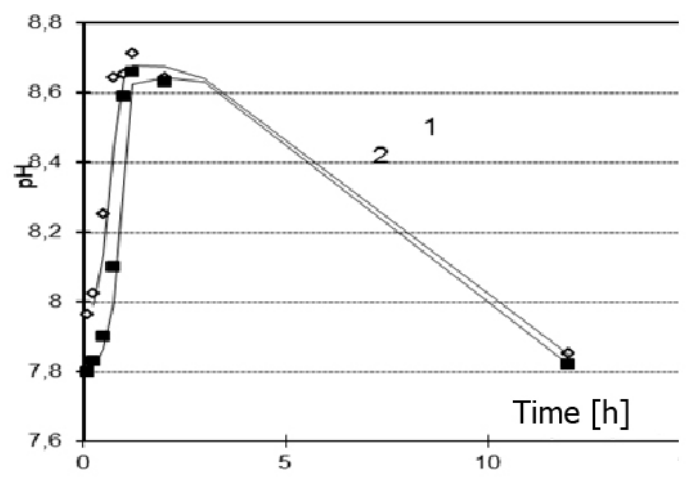

Fig. 2. Variation in $\mathrm{pH}$ in anaerobic conditions: 1 - gravitational separation of sludge; 2 - flotation separation of sludge.

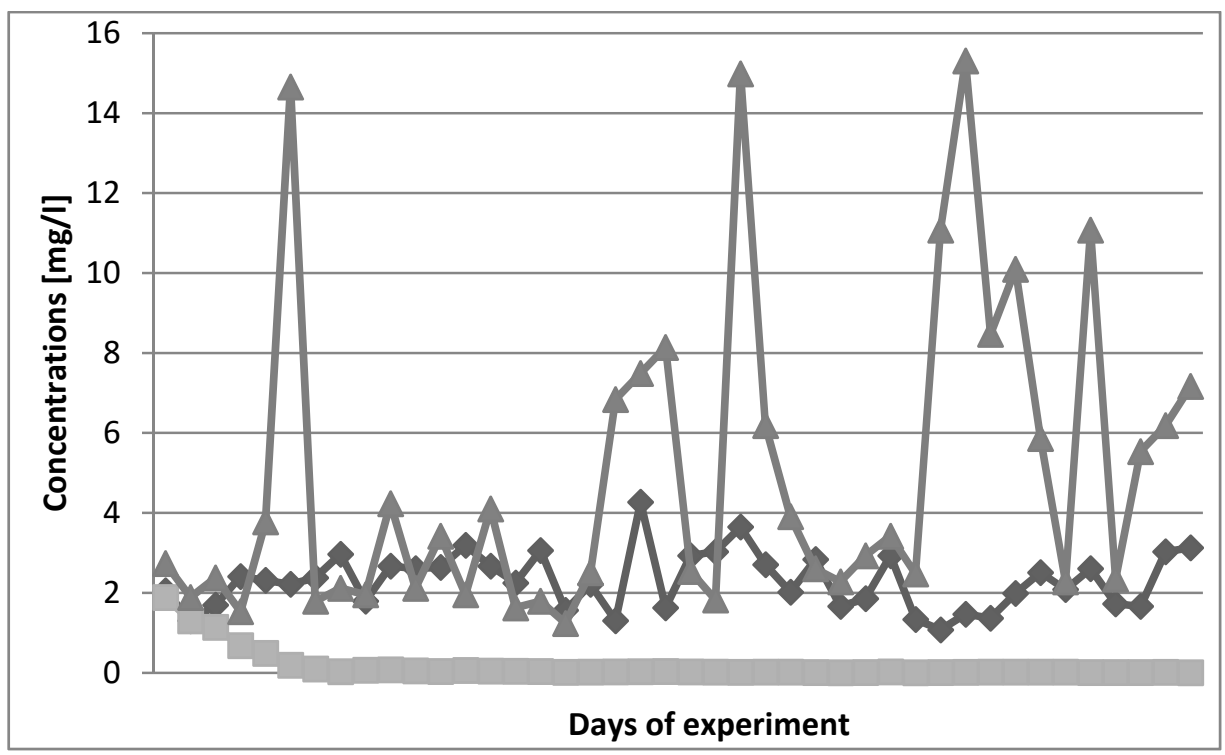

Fig. 3. Concentration of phosphates in semi-periodical process: $\boldsymbol{\Delta}$ - phosphates in incoming wastewater; - phosphates after anaerobic treatment of sludge; $\boldsymbol{-}$ - phosphate in purified wastewater.

In the initial period of releasing phosphate $\mathrm{pH}$ quickly rises, then slowly reduced. This is probably due to the sequential formation of different types of salts - in the first period formed phosphoric average salts of alkali metals, with alkaline reaction, and then - acidic salts. The result of semi-periodical process is presented on Figure 3. As it obvious from data practically full phosphorus removal was reached. Concentration of phosphorus in influent was 2 - $3.5 \mathrm{mgP} / \mathrm{l}$, in decanted water - concentrations increased up to $7-16 \mathrm{mgP} / 1$. In effluent phosphates were practically absent.

After receiving positive results at the lab installation, two paths of development of technologies - contact technology with consistent implementation of treatment processes in 
a single tank and flow mode technology were appeared. The choice was made in favor of flow mode technology as promising technology for high performance buildings.

Study technology for biological removal of phosphorus was conducted on experimental installation with performance $24 \mathrm{~m} 3$ /day on wastewater in Moscow. The main tasks of this phase of the study were to explore the aspects of biological removal of phosphorus in flow mode experimental installation. As a results of this tests it's were determined kinetic parameters of processes phosphorus release and organic matters remove. Significant parameter which effect on speed of the process was original contents of phosphorus compounds, time of anaerobic processing of the recycling sludge. Figure 4 shows the dependence of the residual content of total phosphorus and phosphates in treated water from time anaerobic processing of recycling sludge.

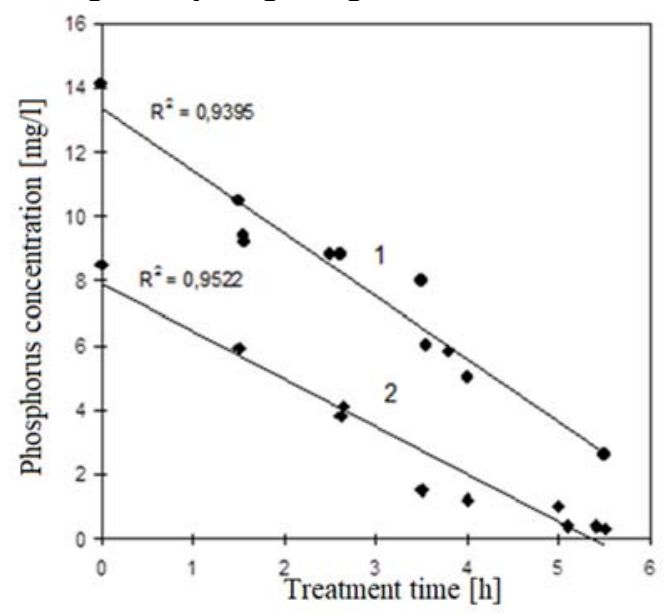

Fig. 4. Treatment time to concentration of phosphorus dependence: 1-total phosphorus; 2-phosphate.

It was found that different taxonomic groups of bacteria possessed the ability to release phosphorus as phosphoric acid in liquid phase. The greatest the ability of discharge of phosphorus has spore bacterium type Cereus.

Table 1. The results of the treatment on experimental installation in biological phosphorus removal

\begin{tabular}{|c|c|c|c|c|c|c|c|c|}
\hline \multirow{3}{*}{ Mode } & Anaerobic processing & \multicolumn{7}{|c|}{ Concentration, $\mathrm{mg} / \mathrm{l}$} \\
\cline { 2 - 9 } & period $[\mathrm{h}]$ & $-\mathrm{P}_{\text {tot }}$ & $\mathrm{PO}_{4}{ }^{3-}$ & $\mathrm{NH}^{+}{ }_{4}$ & $\mathrm{NO}_{3}-$ & $\mathrm{NO}_{2}-$ & $\mathrm{BOD}$ & $\mathrm{COD}$ \\
\hline Control & - & 10.8 & 5.6 & 13.8 & 0.6 & 0.45 & 16 & 94 \\
\hline \multirow{3}{*}{$\begin{array}{c}\text { Biological removal of } \\
\text { phosphorus }\end{array}$} & 1.5 & 8.2 & 5.9 & 26 & 0 & 0.3 & 23 & 86 \\
\cline { 2 - 9 } & 1.5 & 8 & 4.5 & 16.6 & 2 & 1.25 & 23 & 77 \\
\cline { 2 - 9 } & 3.0 & 5.9 & 3.4 & 8.8 & 4.9 & 0.4 & 24 & 60 \\
\cline { 2 - 9 } & 4.5 & 3.2 & 0.2 & 17 & 0.1 & 0.15 & 20 & 70 \\
\cline { 2 - 8 } & 4.5 & 2.5 & 0.3 & 15.6 & 0.1 & 0.09 & 12 & 50 \\
\hline
\end{tabular}

Achieved efficiency of removal phosphorus total was 75-85\%, dissolved phosphate - up to $95 \%$. Concentrations of matters in effluent were: BOD $12-15 \mathrm{mg} / \mathrm{l}$, phosphate $0.1-0.3$ $\mathrm{mg} / \mathrm{l}$, ammonium $17-19 \mathrm{mg} / \mathrm{l}$, nitrate $0.1-0.5 \mathrm{mg} / \mathrm{l}$. Investigational industrial plant in Tichvin town in Leningrad Region has been running for three years in the regime of biological phosphorus removal. During pilot tests of the technology in Tichvin town on structures with capacity of $4500 \mathrm{~m} 3$ /day for three years, confirmed the dependencies, obtained on experimental technology installation. Technology of wastewater treatment of phosphorus has provided stable phosphorus compounds removal up to prescribed limits, despite the substantial fluctuation of their content in the source water. The technology 
required to ensure uniform hydraulic load in aeration tank. Data of phosphate content in influent and effluent during this period are given in Figure 5.

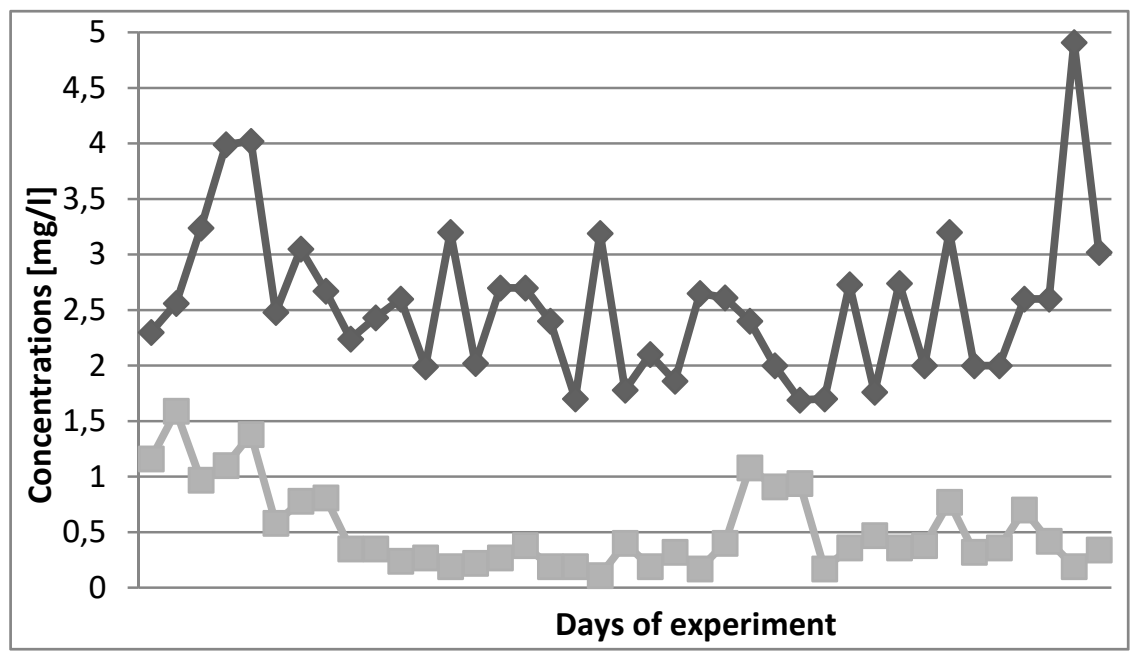

Fig. 5. $\mathrm{P}-\mathrm{PO}_{4}$ concentration in incoming and purified wastewater.

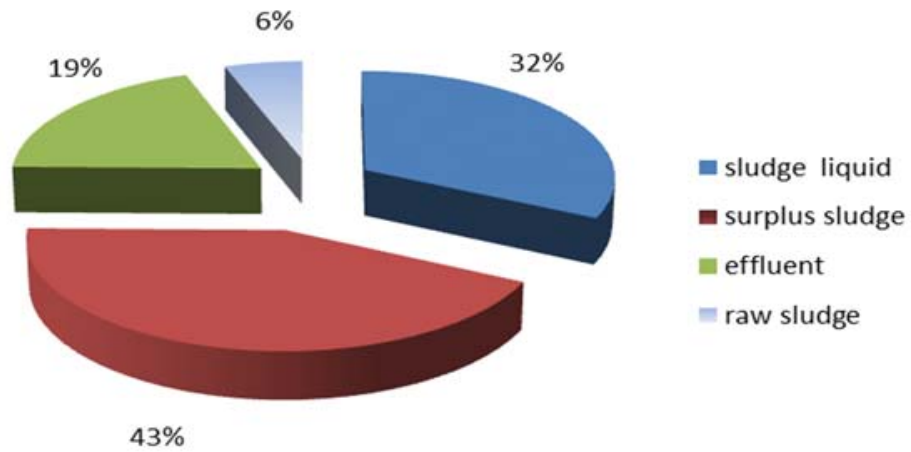

Fig. 6. Total phosphorus in purified wastewater when technology of phosphorus removal by biology.

Data of experiment showed that high efficiency of phosphorus removal had been very resistant. Quality of treated water was rather stable. It was pointed out good removal of some other types of contaminated matters. Treated water had have the following characteristic: BOD 6 - $9 \mathrm{mg} / \mathrm{l}$, COD 58 - $90 \mathrm{mg} / \mathrm{l}$, ammonium - 3.3-9.2 mg/l, nitrates 3.3$5.0 \mathrm{mg} / \mathrm{l}$, phosphates $0.3-0.5 \mathrm{mg} / \mathrm{l}$. Phosphates in the tank of anaerobic treatment of recirculated sludge were $9-12 \mathrm{mg} / \mathrm{l}$. A histogram of quantity of total phosphorus byproducts of the system in a biological phosphorus removal of sewage treatment presented in Figure 6 . As you can see that in excess sludge - $44 \%$, in sludge water $-32 \%$, in raw sludge $5 \%$. In treated water $19 \%$ total phosphorus remained.

At the same time - in effluent compounds of phosphorus consists of dissolved part and insoluble part. In effluent of the dissolved total phosphorus contained in the number of $30 \%$ and $60 \%$ - of phosphorus was suspended solids. Increasing the deepness of the removal of suspended solids in treated water; it is possible to enhance the removal of total phosphorus. Removal of phosphate by the scheme was $95 \%$.

After treatment recirculated sludge in anaerobic tank and at the same time precipitate of sludge, lime was used in decanted water to remove phosphates to get experimental portion of fertilise. Characteristics of the resulting sludge is presented in Table 2. 
Table 2. Composition of the sediment samples.

\begin{tabular}{|c|c|c|c|c|c|}
\hline No. of & \multirow{2}{*}{$\begin{array}{c}\text { Amount, } \\
\text { sample }\end{array}$} & \multicolumn{4}{|c|}{ The composition of sediment, \% } \\
\cline { 3 - 6 } & $\mathrm{mgCaO} / 1$ & $\mathrm{CaO}$ & $\mathrm{P}_{2} \mathrm{O}_{5 \text { tot }}{ }^{*}$ & $\mathrm{P}_{2} \mathrm{O}_{5 \text { cit }}{ }^{* *}$ & $\mathrm{P}_{2} \mathrm{O}_{5 \text { sol. }}$ *** \\
\hline 1 & 100 & 44.8 & 3.63 & 2.91 & 0.04 \\
\hline 2 & 200 & 40.69 & 2.30 & 1.49 & 0.03 \\
\hline 3 & 200 & 40.60 & 2.00 & 1.98 & 0.02 \\
\hline 4 & 400 & 46.64 & 1.63 & 1.6 & 0.01 \\
\hline
\end{tabular}

Note: $* \mathrm{P}_{2} \mathrm{O}_{5 \text { tot }}-$ total phosphorus in sediment, ${ }^{*} \mathrm{P}_{2} \mathrm{O}_{5 \text { cit }}$ - citrate digestible phosphorus in the sludge, **** $\mathrm{P}_{2} \mathrm{O}_{5 \text { sol }}$ - water soluble phosphorus in sludge.

Besides, chemical analyses during vegetation period of agro-chemical tests of phosphorus-calcium sediment was done. Preliminary results of agro-chemical tests showed that the fertiliser was more effective for raps crop than standard lime. Efficiency of using of phosphorus-calcium containing sediment was equal efficiency of lime enriched with superphosphate. The fertiliser positively affected on agrochemical soil properties and facilitated phosphorus accumulation enough for plants. Results of tests for microelements of the fertiliser showed that it can be applied as micro fertilizer. Wide application of biological technology of phosphorus removal from municipal waste water and utilisation of phosphorus - calcium sediment - will allow making further step to restore natural circulation of phosphorus in nature.

The wide application of the technology of biological phosphorus removal using sludge as a soil can contribute to the restoration of the phosphorus cycle in nature.

\section{Conclusions}

1 Application of technology of biological phosphorus removal allows you to ensure the prescribed requirements for the quality for phosphates of purified waste water.

2. The process of biological treatment can implement on existing wastewater treatment plants with slight reconstruction of existing constructions.

3. Technology of deep biological phosphorus removal allows you to gain valuable sediment with properties equal meliorant, enriched superphosphate.

\section{References}

1. SP 32.13330.2012 Sewerage. External networks and constructions (Standartinform, Moscow, 2012)

2. N. Zaletova, Treatment of urban sewage of nutrients (nitrogen and phosphorus) (DSc thesis, Moscow, 1999)

3. Yu.Yu. Lurie Uniform methods of analysis (Chemistry, Moscow, 1975).

4. Babenkov E.D. Coagulants water purification (Nauka, Moscow, 1975)

5. Rabotnova I.1. General Microbiology (Mir, Moscow, 1982)

6. Kondratiev K.J., Koplan Dicks I.S. Evolution cycles of phosphorus and eutrophication of natural waters (Nauka, Leningrad, 1988).

7. N.A. Zaletova, Water supply and sanitary technique, 11, 40-46 (2011)

8. N.A. Zaletova, Water and ecology. Problems and solutions, 2, 49-55 (2000)

9. Zaletova N.A., Isayeva N.V., Effective removal of phosphorus from municipal wastewater (ONTI APS, Moscow, 1988) 